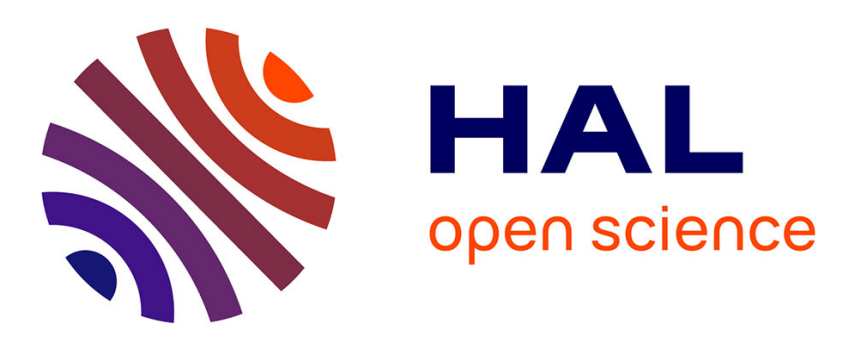

\title{
Observation of far-field Mach waves generated by the 2001 Kokoxili supershear earthquake,
}

\author{
M. Vallée, E.M. Dunham
}

\section{To cite this version:}

M. Vallée, E.M. Dunham. Observation of far-field Mach waves generated by the 2001 Kokoxili supershear earthquake,. Geophysical Research Letters, 2012, 39 (5), pp.L05311. 10.1029/2011GL050725 . hal-01053146

\section{HAL Id: hal-01053146 https://hal.science/hal-01053146}

Submitted on 19 May 2017

HAL is a multi-disciplinary open access archive for the deposit and dissemination of scientific research documents, whether they are published or not. The documents may come from teaching and research institutions in France or abroad, or from public or private research centers.
L'archive ouverte pluridisciplinaire HAL, est destinée au dépôt et à la diffusion de documents scientifiques de niveau recherche, publiés ou non, émanant des établissements d'enseignement et de recherche français ou étrangers, des laboratoires publics ou privés. 


\title{
Observation of far-field Mach waves generated by the 2001 Kokoxili supershear earthquake
}

\author{
M. Vallée ${ }^{1}$ and Eric M. Dunham ${ }^{2}$ \\ Received 21 December 2011; revised 13 February 2012; accepted 13 February 2012; published 14 March 2012.
}

[1] Regional surface wave observations offer a powerful tool for determining source properties of large earthquakes, especially rupture velocity. Supershear ruptures, being faster than surface wave phase velocities, create far-field surface wave Mach cones along which waves from all sections of the fault arrive simultaneously and, over a sufficiently narrow frequency band, in phase. We present the first observation of far-field Mach waves from the major Kokoxili earthquake (Tibet, 2001/11/14, $M_{w}$ 7.9) and confirm that ground motion amplitudes are indeed enhanced on the Mach cone. Theory predicts that on the Mach cone, bandpassed surface wave seismograms from a large supershear rupture will be identical to those from much smaller events with similar focal mechanisms, with an amplitude ratio equal to the ratio of the seismic moments of the two events. Cross-correlation of 15-25 s Love waves from the Kokoxili event with those from a much smaller $\left(M_{w} 5\right)$ foreshock indicates a high degree of similarity (correlation coefficients ranging from 0.8 to 0.95 ) in waveforms recorded at stations near the far-field Mach cone. This similarity vanishes away from the Mach cone. These observations provide further evidence for supershear propagation of the Kokoxili rupture, and demonstrate how this simple waveform correlation procedure can be used to identify supershear ruptures. Citation: Vallée, M., and E. M. Dunham (2012), Observation of far-field Mach waves generated by the 2001 Kokoxili supershear earthquake, Geophys. Res. Lett., 39, L05311, doi:10.1029/2011GL050725.

\section{Introduction}

[2] The speed at which an earthquake rupture propagates influences the amplitude and character of the radiated wavefield. Rupture velocities less than the shear wave speed $\beta$ are typically inferred by source inversions and seismic imaging studies. In fact, $\beta$ is the limiting velocity in certain geometries, including along-strike propagation of megathrust ruptures in subduction zones. However, under mode II loading conditions, in which slip occurs parallel to the rupture propagation direction, rupture velocities in excess of $\beta$ become possible [Burridge, 1973; Andrews, 1976; Xia et al., 2004]. Seismic studies suggest supershear rupture velocities in several major strike-slip earthquakes (Izmit, Turkey, 1999; Kokoxili, Tibet, 2001; Denali, Alaska, 2002) [Bouchon et al., 2001; Bouchon and Vallée, 2003; Ellsworth et al., 2004;

\footnotetext{
${ }^{1}$ Geoazur, University of Nice Sophia-Antipolis, IRD, OCA, Valbonne, France.

${ }^{2}$ Department of Geophysics and Institute for Computational and Applied Mathematics, Stanford University, Stanford, California, USA.

Copyright 2012 by the American Geophysical Union. 0094-8276/12/2011GL050725
}

Dunham and Archuleta, 2004; Aagaard and Heaton, 2004; Robinson et al., 2006; Vallée et al., 2008; Walker and Shearer, 2009].

[3] The most distinctive features of supershear ruptures are Mach fronts. These sharp wavefronts occur whenever the source propagates faster than the speed of the waves it radiates. Supershear ruptures thus produce shear wave Mach fronts [Freund, 1979; Ben-Menahem and Singh, 1987], as well as surface wave Mach fronts for ruptures in a half-space [Dunham and Bhat, 2008]. These Mach fronts are predicted to transport extremely large particle velocities and stress perturbations out to distances comparable to the fault width [Bernard and Baumont, 2005; Dunham and Bhat, 2008], though this effect has not been substantiated observationally, possibly due to lack of Mach front coherence [Bizzarri et al., 2010; Andrews, 2010].

[4] Thus far, almost all theoretical and numerical studies have focused on the wavefield in the near-source region (i.e., distances within a few source dimensions). In this work we explore properties of Mach waves in the far-field limit. Our focus is on surface waves, which carry the largest ground motion amplitudes outside the near-source region. In particular, we characterize how waves radiated by different sections of the fault interfere with each other, and how this leads to extreme amplification of surface wave motions at stations located along the far-field Mach cone. This directivity pattern is quite different from that of subshear ruptures, which features maximum amplification in the forward direction.

[5] We next prove that at stations along the far-field Mach cone, narrowband seismograms from a large supershear earthquake will be identical to those from a small earthquake of similar focal mechanism (except for an overall amplitude difference equal to the ratio of seismic moments). We test our theoretical predictions using regional Love wave records from the Kokoxili earthquake, and confirm that maximum directivity effects indeed occur at stations located along the far-field Mach cone.

\section{Far-Field Surface Waves From Supershear Ruptures}

[6] In this section we discuss the relationship between farfield surface waves from a large supershear earthquake and a small earthquake located in the vicinity of the large one. Both earthquakes have identical focal mechanisms corresponding to horizontal slip on vertically dipping faults.

[7] First consider the small earthquake with seismic moment $m_{0}$. At sufficiently low frequencies, seismic wavelengths are larger than the source dimension and the earthquake can be described with the point source moment density $m_{0} \delta(\mathbf{x}) H(t)$, where $\delta(\cdot)$ and $H(\cdot)$ are the delta function and 
unit step function, respectively. Within the approximation of a layered medium (i.e., neglecting lateral heterogeneity in material properties), the far-field displacement spectrum corresponding to fundamental mode surface waves can be written in the form [Aki and Richards, 2002]

$$
\hat{u}_{i}\left(r_{0}, \phi, \omega\right)=m_{0} \hat{F}_{i}\left(r_{0}, \phi, \omega\right) e^{i k r_{0}},
$$

where $r_{0}=|\mathbf{x}|$ and $\phi$ are the distance and azimuthal angle between the source (at the origin) and the station, and $\omega$ is the natural frequency. The excitation function $\hat{F}_{i}\left(r_{0}, \phi, \omega\right)$ and wavenumber $k=k(\omega)$ are specific to the fundamental surface wave eigenmode, with the former also depending on the focal mechanism of the earthquake.

[8] Now consider a much larger earthquake, in the vicinity of the small one, involving unilateral rupture propagation at constant rupture velocity $v_{r}$. The seismic moment $M_{0}$ is released over width $W$ and length $L(0 \leq x \leq L)$. At frequencies less than $\sim \beta / W$, seismic wavelengths are larger than $W$ and the source can be described in terms of the depth-averaged slip $\Delta u(x)$. The far-field surface wave displacement spectrum, in the far-field limit [Aki and Richards, 2002], is

$$
\hat{U}_{i}\left(r_{0}, \phi, \omega\right)=\mu W \hat{F}_{i}\left(r_{0}, \phi, \omega\right) e^{i k r_{0}} \int_{0}^{L} \Delta u(x) e^{i \omega x / v_{r}-i k \cos \phi} d x,
$$

where $\mu$ is the shear modulus. We have introduced the phase factors $e^{i \omega x / v_{r}}$ and $e^{-i k x \cos \phi}$ to account for variations in surface wave arrival times due to both the rupture time and source-receiver distance, respectively, for points along the length of the fault.

[9] Using (1) to eliminate the excitation function, we rewrite (2) as

$$
\hat{U}_{i}\left(r_{0}, \phi, \omega\right)=\hat{u}_{i}\left(r_{0}, \phi, \omega\right) \frac{\mu W}{m_{0}} \int_{0}^{L} \Delta u(x) e^{2 i x X(\phi, \omega) / L} d x,
$$

where

$$
X(\phi, \omega) \equiv \frac{\omega L}{2 v_{r}}\left[1-\frac{v_{r} \cos \phi}{c(\omega)}\right]
$$

captures the directivity effect involving the ratio of the rupture velocity $v_{r}$ to the surface wave phase velocity $c(\omega) \equiv \omega / k(\omega)$.

[10] When $v_{r}<c(\omega)$, then receivers at any azimuth $\phi$ record wave arrivals in the chronological order in which they were emitted by the rupture; i.e., the first arrivals are from the hypocenter and the last are from the end of the fault. Maximum directivity effects occur at stations in the forward direction $(\phi \approx 0)$. In contrast, for $v_{r}>c(\omega)$ there exist two distinct regions bounded by $\phi= \pm \phi_{M}(\omega)$, where

$$
\phi_{M}(\omega) \equiv \arccos \left(c(\omega) / v_{r}\right)
$$

is half the opening angle of the far-field Mach cone. Within the Mach cone (i.e., $|\phi|<\phi_{M}(\omega)$ ), the first arriving waves come from the last section of the fault to rupture, and waves from the hypocenter arrive last. On the Mach cone itself, waves from all sections of the fault arrive simultaneously and interfere constructively. The resulting amplification of ground motion exceeds that caused by even the fastest subshear ruptures.
[11] The Mach angle $\phi_{M}(\omega)$ is the value of $\phi$ for which $X(\phi, \omega)=0$. Thus from (3) we see that on the Mach cone (and only on it), the displacement spectrum of the large earthquake is identical to that of the small earthquake:

$$
\hat{U}_{i}\left(r_{0}, \phi_{M}(\omega), \omega\right)=\left(M_{0} / m_{0}\right) \hat{u}_{i}\left(r_{0}, \phi_{M}(\omega), \omega\right)
$$

a result that holds even for spatially variable slip in the large event since $M_{0} \equiv \mu W \int_{0}^{L} \Delta u(x) d x$. While a similar result holds for all $\phi$ at frequencies less than $\sim \beta / L$ (because $|X(\phi, \omega)| \ll 1)$, we emphasize that (6) applies at frequencies less than $\sim \beta / W$. For large strike-slip earthquakes, this includes periods greater than about $5 \mathrm{~s}$ (considering $W$ equal to $15 \mathrm{~km}$ and a shear wave speed of $3 \mathrm{~km} / \mathrm{s}$ ), rather than just those greater than $\sim 100 \mathrm{~s}$.

[12] Since surface wave phase velocities $c(\omega)$ are slightly less than the shear wave speed $\beta$, then the surface wave Mach cone will exist for supershear earthquakes (for which $v_{r}>\beta$ ). Since the Mach angle (5) depends on frequency, observational confirmation of our theory is facilitated by working with a limited frequency band centered on $\omega=\omega_{0}$ over which the average surface wave phase velocity is $\bar{c} \approx c\left(\omega_{0}\right)$. The corresponding Mach angle is $\bar{\phi}_{M} \approx \phi_{M}\left(\omega_{0}\right)$. For bandpassed signals recorded at stations along the Mach cone, we can inverse Fourier transform (6) to obtain the remarkable result

$$
U_{i}\left(r_{0}, \bar{\phi}_{M}, t\right) \approx\left(M_{0} / m_{0}\right) u_{i}\left(r_{0}, \bar{\phi}_{M}, t\right) .
$$

At these stations, the bandpassed seismogram from the large event is predicted to match that of the small event, up to an overall normalization factor that is the ratio of the moments of the two events.

[13] To summarize, in the case of a long unilateral rupture $(L \gg W)$ observed in the far field $\left(r_{0} \gg L\right)$, three key observations provide evidence for Mach waves and thus proof that an earthquake is supershear: (1) Bandpassed waveforms from the large and small events are proportional at stations in particular azimuthal directions (which define the far-field Mach cone). (2) On the Mach cone, the amplitude ratio of these waveforms (or their spectral amplitude) is equal to the moment ratio. (3) In all other directions, the waveforms of the large earthquake are more complex than those of the small one. The amplitude ratio also decreases because signals from the large event are spread in time and waves from different parts of the fault are subject to more destructive interference. This is substantially different than the directivity pattern for subshear ruptures, for which directivity is maximized in the forward direction $(\phi=0)$ and decreases monotonically as $|\phi|$ is increased to $180^{\circ}$.

\section{Observation of Mach Waves From the Kokoxili Earthquake}

[14] The left-lateral strike-slip Kokoxili earthquake (Tibet, $2001 / 11 / 14, M_{w} 7.9$ ) is probably the earthquake for which the indications of supershear propagation are most numerous [Bouchon and Vallée, 2003; Robinson et al., 2006; Vallée et al., 2008; Walker and Shearer, 2009]. It ruptured a $350-400-\mathrm{km}$-long segment of the Kunlun fault. The fault geometry (Figure 1) has been accurately determined by field investigation and satellite imaging [Klinger et al., 2005; Lasserre et al., 2005; Xu et al., 2006]. 


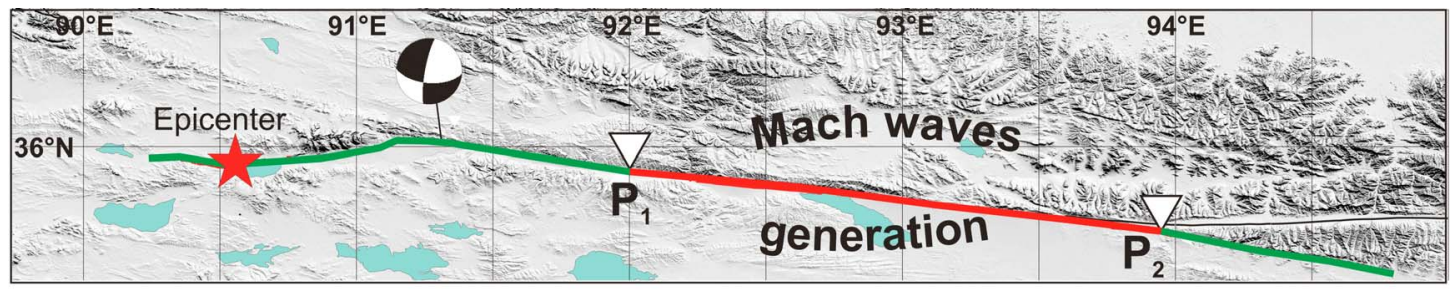

Figure 1. Fault rupture in the 2001 Kokoxili earthquake, with subshear rupture velocities on green segments and supershear velocities on red segments. The 170-km-long supershear segment between points $P_{1}$ and $P_{2}$ is the source region for the Mach waves. The epicenter (star) and focal mechanism are also shown.

[15] The rupture propagated unilaterally from west to east over about $100 \mathrm{~s}$. After $130 \mathrm{~km}$ of subshear propagation, the rupture jumped into the supershear regime [Vallée et al., 2008; Walker and Shearer, 2009; Robinson et al., 2006]. The average rupture velocity over the following $170-\mathrm{km}$ long segment (bounded by points $P_{1}$ and $P_{2}$ in Figure 1) has been determined to be between 5 and $6.5 \mathrm{~km} / \mathrm{s}$, a value clearly higher the $3.5 \mathrm{~km} / \mathrm{s}$ crustal shear wave velocity. The rupture velocity in the last part of the earthquake is less well known, but appears to be subshear.

[16] The Kokoxili earthquake, as well as a similar but much smaller foreshock $\left(2000 / 11 / 26, M_{w}\right.$ 5) located nearby, were recorded by several regional broadband seismometers belonging to the Federation of Digital Seismometers Network (FDSN; Figure 2). Because of the strike-slip character of the two earthquakes, the dominant waves are dispersive Love waves. We focus on 15-25 s Love waves to limit the effects of dispersion (see previous section). The average phase velocity $\bar{c}$ in this period range can be estimated from the recent regional group velocity maps derived from earthquakes [Chen et al., 2010] or seismic noise [Li et al., 2011]. This estimation can be made using the average value of $3.5 \mathrm{~km} / \mathrm{s}$ for the phase velocity of the $25 \mathrm{~s}$ Love waves in the Kunlun fault area (GDM52 model of Ekström [2011]), and the relation between group and phase velocities. Also taking into account the variability of group velocity in the $\mathrm{Li}$ et al. [2011] model around the Kunlun fault, $\bar{c}=3.3 \pm 0.2 \mathrm{~km} / \mathrm{s}$. Acceptable values of $\bar{c}$, along with the possible values of rupture velocity $v_{r}$ in the supershear regime, enable us to predict the geometry of the far-field Love wave Mach cone (Figure 2).

[17] Three stations (ULN, HIA, and KMI) are on the farfield Mach cone. In Figure 3 we show that at these stations, waveforms from the main shock are very similar to those of the small foreshock, as theoretically predicted. After aligning in time the Love wave arrivals, the normalized crosscorrelation coefficient for the entire Love wave train exceeds 0.8 at these three stations, and even reaches 0.95 at station ULN. Moreover, when taking into account the amplifying factor applied in Figure 3, we observe that the amplitude ratio on the Mach cone is approximately 13,000-16,000. The predicted moment ratio between the events is 22,000 , which is larger than the observed ratio. This discrepancy can be explained by the fact that the first segment of the Kokoxili event ruptured at a subshear speed. Generalizing the theory presented in the previous section to a compound rupture containing segments with different rupture speeds is straightforward, and for this specific earthquake we find that $20 \mathrm{~s}$ Love waves from the first (subshear) segment interfere destructively at stations along the Mach cone and contribute little to the overall waveform. Thus, only the supershear segment needs to be considered, and it likely released 60 $80 \%$ of the overall moment [Lasserre et al., 2005; Robinson et al., 2006]. This reduces the expected moment ratio to values close to those observed.

[18] We also find that the cross-correlation values and the amplitude ratios are quite small for stations away from the Mach cone (either inside or outside it). As expected, both of these values reach a minimum when the stations are the furthest from the Mach cone (here for stations ENH and $\mathrm{XAN}$, which are in the forward direction). Taken together,

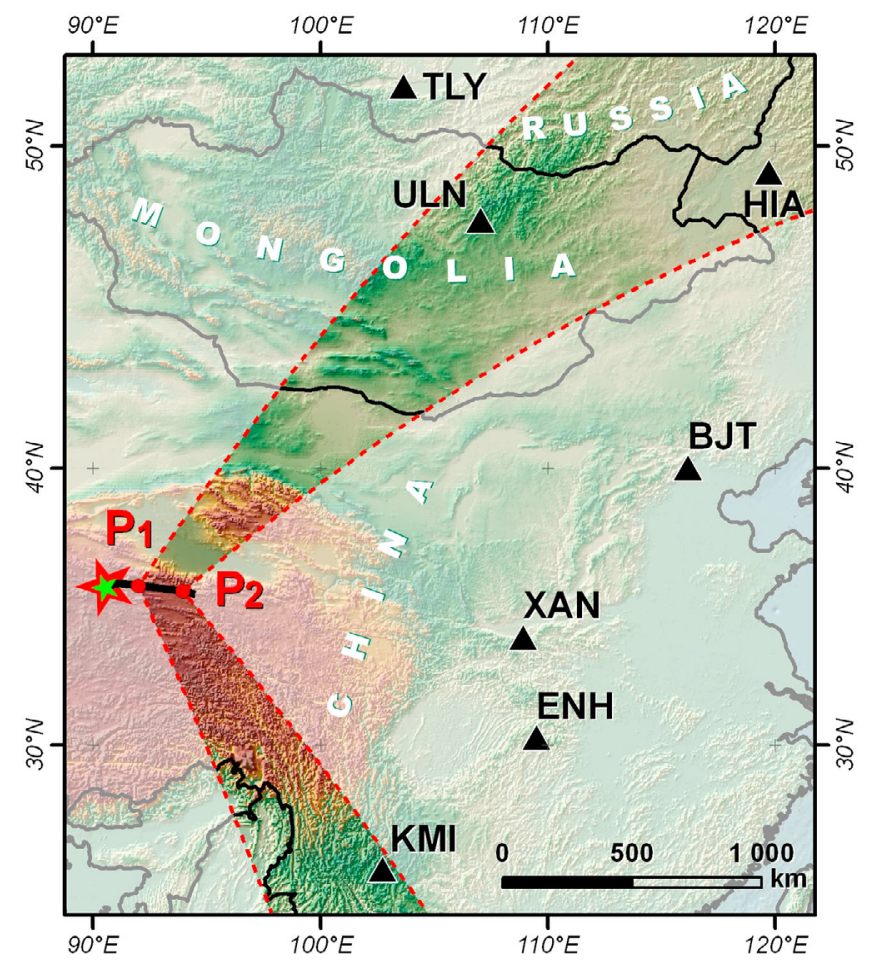

Figure 2. Geometry of the far-field Mach cone. The Kokoxili earthquake epicenter is shown by the red star and the ruptured fault by the black line. The small earthquake is represented only by its epicenter (green star) because it has a negligible extent. The supershear segment is bounded by the points $P_{1}$ and $P_{2}$. The Mach cone location, represented by the shaded area inside the red dashed lines, takes into account uncertainties in Love wave phase velocity and rupture velocity. The location and name of the broadband seismometers are indicated on the map. 


\section{5-25s Love waves}
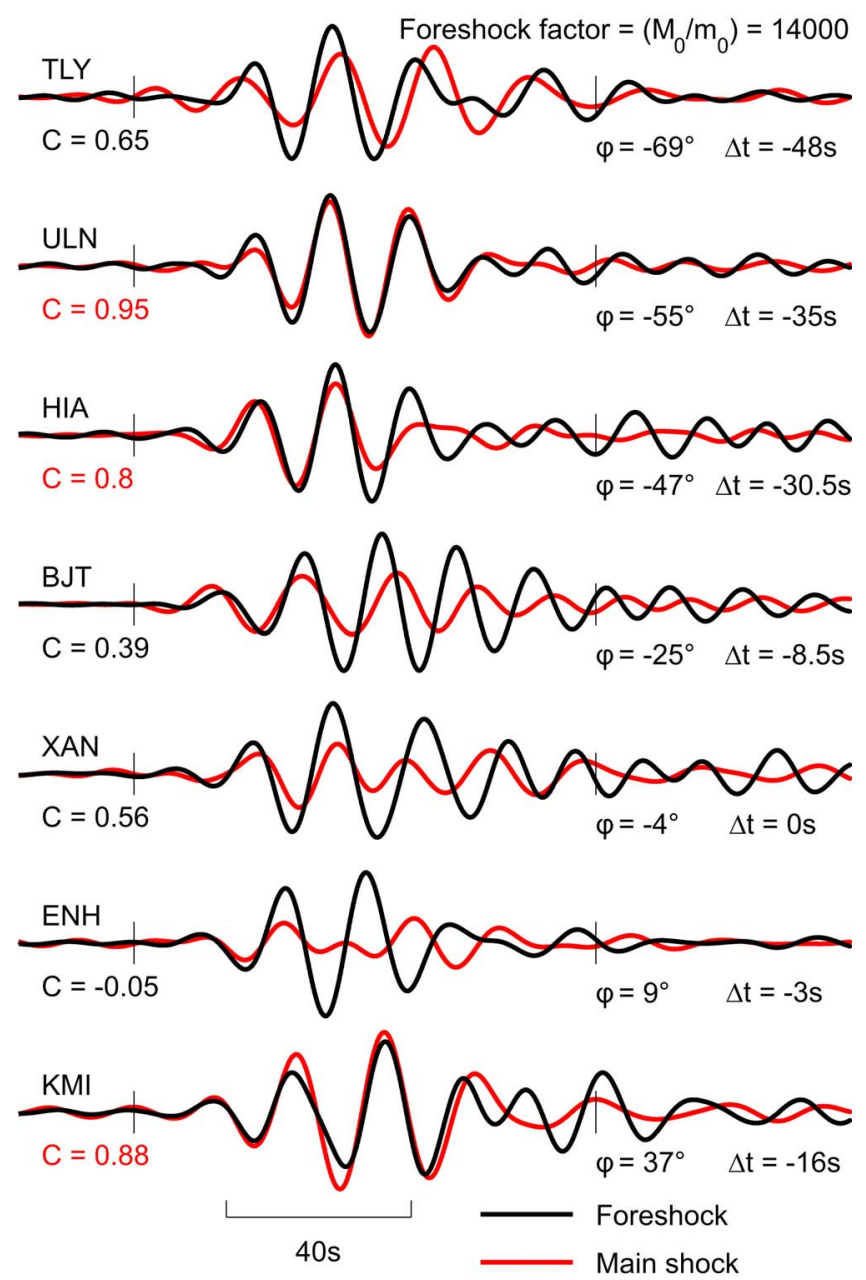

Figure 3. Love wave velocity seismograms from the Kokoxili earthquake (red) and a small foreshock (black), in the $15-25 \mathrm{~s}$ period range. $\phi, \mathrm{C}$, and $\Delta t$ are respectively the station azimuth relative to the rupture direction, the zerolag normalized cross-correlation calculated between the two ticks, and the time shift applied in order to align the records. Negative time shifts imply that the original main shock records are delayed, which is due to the initial subshear segment of the Kokoxili earthquake. Foreshock signals are scaled by an amplifying factor, equal to the inferred ratio of seismic moments of the supershear segment and the foreshock. Note the close similarity in amplitude and phase at stations on the Mach cone.

these results provide direct evidence of far-field Mach waves and thus supershear rupture speeds over a large section of the Kunlun fault.

\section{Discussion}

[19] We have developed a simple observational procedure using regional surface waves that discriminates between subshear and supershear rupture speeds for long strike-slip earthquakes. Because the model assumes seismic wavelengths greater than the fault width $(\approx 10-15 \mathrm{~km})$, the method is valid for periods greater than about $5 \mathrm{~s}$ and resolves supershear propagation over sections of the fault that are several times longer than the fault width. For these intermediate and long periods, our approach directly enlightens how the seismic radiation is greatly enhanced on the Mach cone. Moreover, our procedure has additional advantages: it is free from nonuniqueness issues associated with kinematic finite fault inversions and also provides a direct estimate of the moment released during supershear propagation, which helps constrain the length of the supershear segment.

[20] Acknowledgments. We thank IRIS for public and easy access to the data, P. Bernard, A. Ferreira, J.M. Nocquet and M. Bouchon for helpful comments, J. Trévisan and Y. Klinger for their help in designing some figures of this article. The review of the paper by Brad Aagaard has been very valuable.

[21] The Editor thanks Shamita M. Das and Brad Aagaard for their assistance in evaluating this paper.

\section{References}

Aagaard, B. T., and T. H. Heaton (2004), Near-source ground motions from simulations of sustained intersonic and supersonic fault ruptures, Bull. Seismol. Soc. Am., 94(6), 2064-2078.

Aki, K., and P. Richards (2002), Quantitative Seismology, Univ. Sci., Sausalito, Calif.

Andrews, D. J. (1976), Rupture velocity of plane strain shear cracks, J. Geophys. Res., 81(32), 5679-5687, doi:10.1029/JB081i032p05679.

Andrews, D. J. (2010), Ground motion hazard from supershear rupture, Tectonophysics, 493, 216-221, doi:10.1016/j.tecto.2010.02.003.

Ben-Menahem, A., and S. J. Singh (1987), Supershear accelerations and Mach-waves from a rupturing front: Part 1. Theoretical model and implications, J. Phys. Earth, 35, 347-365.

Bernard, P., and D. Baumont (2005), Shear Mach wave characterization for kinematic fault rupture models with constant supershear rupture velocity, Geophys. J. Int., 162(2), 431-447, doi:10.1111/j.1365-246X.2005.02611.x.

Bizzarri, A., E. M. Dunham, and P. Spudich (2010), Coherence of Mach fronts during heterogeneous supershear earthquake rupture propagation: Simulations and comparison with observations, J. Geophys. Res., 115, B08301, doi:10.1029/2009JB006819.

Bouchon, M., and M. Vallée (2003), Observation of long supershear rupture during the magnitude 8.1 Kunlunshan earthquake, Science, 301(5634), 824-826, doi:10.1126/science. 1086832 .

Bouchon, M., M. Bouin, H. Karabulut, M. N. Toksöz, M. Dietrich, and A. J. Rosakis (2001), How fast is rupture during an earthquake? New insights from the 1999 Turkey Earthquakes, Geophys. Res. Lett., 28(14), 2723-2726, doi:10.1029/2001GL013112.

Burridge, R. (1973), Admissible speeds for plane-strain shear cracks with friction but lacking cohesion, Geophys. J. R. Astron. Soc., 35(4), 439-455, doi:10.1111/j.1365-246X.1973.tb00608.x.

Chen, Y., J. Badal, and J. Hu (2010), Love and Rayleigh wave tomography of Qinghai-Tibet plateau and its surrounding areas, Pure Appl. Geophys., 167(10), 1171-1203, doi:10.1007/s00024-009-0040-1.

Dunham, E. M., and R. J. Archuleta (2004), Evidence for a supershear transient during the 2002 Denali Fault earthquake, Bull. Seismol. Soc. Am., 94(6B), S256-S268, doi:10.1785/0120040616.

Dunham, E. M., and H. S. Bhat (2008), Attenuation of radiated ground motion and stresses from three-dimensional supershear ruptures, J. Geophys. Res., 113, B08319, doi:10.1029/2007JB005182.

Ekström, G. (2011), A global model of Love and Rayleigh surface wave dispersion and anisotropy, 25-250 s, Geophys. J. Int., 187(3), 1668-1686, doi:10.1111/j.1365-246X.2011.05225.x.

Ellsworth, W. L., et al. (2004), Near-field ground motion of the 2002 Denali Fault, Alaska, earthquake recorded at Pump Station 10, Earthquake Spectra, 20(3), 597-615, doi:10.1193/1.1778172.

Freund, L. B. (1979), The mechanics of dynamic shear crack propagation, J. Geophys. Res., 84(B5), 2199-2209, doi:10.1029/JB084iB05p02199.

Klinger, Y., X. Xu, P. Tapponnier, J. Van der Woerd, C. Lasserre, and G. King (2005), High-resolution satellite imagery mapping of the surface rupture and slip distribution of the $M_{w} \sim 7.8$, November 14, 2001 Kokoxili earthquake (Kunlun fault, northern Tibet, China), Bull. Seismol. Soc. Am., 95(5), 1970-1987, doi:10.1785/0120040233.

Lasserre, C., G. Peltzer, F. Crampé, Y. Klinger, J. Van der Woerd, and P. Tapponnier (2005), Coseismic deformation of the $2001 M_{w}=7.8$ Kokoxili earthquake in Tibet, measured by synthetic aperture radar interferometry, J. Geophys. Res., 110, B12408, doi:10.1029/2004JB003500.

Li, H., S. Li, X. D. Song, M. Gong, X. Li, and J. Jia (2011), Crustal and uppermost mantle velocity structure beneath northwestern China from 
seismic ambient noise tomography, Geophys. J. Int., 188, 131-143, doi:10.1111/j.1365-246X.2011.05205.x.

Robinson, D. P., C. Brough, and S. Das (2006), The Mw 7.8, 2001 Kunlunshan earthquake: Extreme rupture speed variability and effect of fault geometry, J. Geophys. Res., 111, B08303, doi:10.1029/2005JB004137.

Vallée, M., M. Landès, N. M. Shapiro, and Y. Klinger (2008), The 14 November 2001 Kokoxili (Tibet) earthquake: High-frequency seismic radiation originating from the transitions between sub-Rayleigh and supershear rupture velocity regimes, J. Geophys. Res., 113, B07305, doi:10.1029/2007JB005520.

Walker, K. T., and P. M. Shearer (2009), Illuminating the near-sonic rupture velocities of the intracontinental Kokoxili $M_{w} 7.8$ and Denali fault $M_{w} 7.9$ strike-slip earthquakes with global $\mathrm{P}$ wave back projection imaging, $J$. Geophys. Res., 114, B02304, doi:10.1029/2008JB005738.
Xia, K., A. J. Rosakis, and H. Kanamori (2004), Laboratory earthquakes: The sub-Rayleigh-to-supershear transition, Science, 303(5665), 1859-1861, doi:10.1126/science.1094022.

Xu, X., G. Yu, Y. Klinger, P. Tapponnier, and J. Van Der Woerd (2006), Reevaluation of surface rupture parameters and faulting segmentation of the 2001 Kunlunshan earthquake $\left(M_{w} 7.8\right)$, northern Tibetan Plateau, China, J. Geophys. Res., 111, B05316, doi:10.1029/2004JB003488.

E. M. Dunham, Department of Geophysics, Stanford University, 397 Panama Mall, Stanford, CA 94305, USA.

M. Vallée, Geoazur, University of Nice Sophia-Antipolis, IRD, OCA, 250 rue Albert Einstein, F-06560 Valbonne CEDEX, France. (vallee@geoazur. unice.fr) 